\title{
An Optimal Design of a Small Photovoltaic Plant with Cost Minimization based on a Real Database of PV Panels and Inverters
}

\author{
${ }^{1}$ GEORGE J. TSEKOURAS, ${ }^{1}$ PANAGIOTA M. DELIGIANNI, ${ }^{1}$ GEORGE A. VOKAS, \\ ${ }^{1}$ ANTONIOS X. MORONIS, ${ }^{1,2}$ CONSTANTINOS D. TSIREKIS, ${ }^{1,3}$ ANASTASIOS D. SALIS, \\ ${ }^{1,4}$ CHRISTOS N. BOLAKIS \\ ${ }^{1}$ Department of Electrical \& Electronics Engineering, Faculty of Engineering, University of West \\ Attica, GREECE \\ ${ }^{2}$ Transmission New Projects Department, Hellenic Independent Power Transmission Operator, \\ Dyrrachiou 89 \& Kifissou, Athens, GR-10443, GREECE \\ ${ }^{3}$ Information and Communication Technology Department, Ministry of Migration and Asylum, 196- \\ 198 Thivon Av., Agios Ioannis Rentis-Athens, GR-18233, GREECE \\ ${ }^{4}$ Center for Security Studies, Hellenic Ministry of Citizen Protection, P. Kanellopoulou 4, Athens, \\ GR-11527, GREECE
}

\begin{abstract}
The penetration of renewable energy sources and the development of autonomous power systems for the supply of isolated consumers find applications such as covering energy needs in lighthouses, small islands, monasteries, and even isolated special industrial facilities. Power plant cost is a major limitation in the development of these systems. For example, although the electromechanical cost of photovoltaic plants has been significantly reduced in recent years, however the land cost is not considered, which is a significant expenditure. In this paper, the real problem of an autonomous power station design for the supply of the shoreline electrode substation on the Stachtorroi islet of Attica, is taken as the starting point. The electrode substation is part of the Attica-Crete high voltage direct current (HVDC) electrical interconnection project. For the above problem, an overall evaluation algorithm for a photovoltaic (PV) plant is proposed that considers the technical characteristics of the plant, the installation and operating costs (including land costs in addition to electromechanical costs and efficiency of each of the plants components), as well as the actual commercial data of the individual key elements (PV panels, inverters) of various companies, choosing the optimal system through exhaustive search depending on the required power and the deflated capital reduction interest rate.
\end{abstract}

Key-Words: - autonomous power system, photovoltaic power plant, techno-economic evaluation, optimization

Received: February 4, 2021. Revised: July 29, 2021. Accepted: August 21, 2021. Published: September 14, 2021.

\section{Introduction}

In recent years the development of autonomous power systems using mainly renewable energy sources (RES) in combination with energy storage systems have found several applications including the power supply of simple machines, e.g., radio transmitters [1], small households of some $\mathrm{kW}$ [2], poultry farms [3] and oil wells [4] of some hundreds of $\mathrm{kW}$, as well as ships [5] and isolated islands [6] of some MW. Extensive research has been done on optimization methods for dimensioning through exhaustive search methods [7-8], metaheuristic algorithms [1], Gray Wolf Optimizer [9], Particle Swarm Optimization [9], Jaya algorithm [10], KrillHerd algorithm [10], Ant Lion Optimizer [10] and many others or with ready-made programming packages such as HOMER [4, 11]. In addition, issues of optimal operation [12], control system [13], battery ageing [8], reliability $[7,10]$ have been studied, considering in most cases given the RES cost function with an emphasis on electromechanical installations. However, the penetration of RES encounters important limitations. For example, wind turbines have wind potential availability limitations, elevation limitations due to terrain or neighbouring structures, environmental restrictions (passing migratory birds, etc.), in photovoltaic plants there are solar radiation availability limitations, shadow problems, etc. Additionally, one parameter that is almost always ignored is the area consumed, as a coal power plant requires 50 to $80 \mathrm{~m}^{2} / \mathrm{MW}$, a gas turbine plant 10 to $20 \mathrm{~m}^{2} / \mathrm{MW}$, a combined cycle power plant 25 to 40 $\mathrm{m}^{2} / \mathrm{MW}$, a wind power plant park 2000 to 4000 $\mathrm{m}^{2} / \mathrm{MW}$ and a PV station 5000 to $10000 \mathrm{~m}^{2} / \mathrm{MW}$. Especially PV stations require much larger land, so the cost of land or even the loss of income from their installation must be considered. 
The impact of finding the necessary land area for the installation of PV panels, was raised as a concern during the configuration of the autonomous power station for the supply of the shoreline electrode substation, for the isolated and uninhabited islet of Stachtoroi in the Argosaronic Gulf of Attica, Greece, which is an integral part of the Attica-Crete HVDC electrical interconnection in Greece [8]. It is a building of about $100 \mathrm{~m}^{2}$, which has a mean load demand between $0,5 \mathrm{~kW}$ and $4,1 \mathrm{~kW}$ and peak demand load between 4,8 and $22,3 \mathrm{~kW}$ depending on the climate conditions (winter, summer, spring/autumn) and the operating mode (autonomous mode using battery and PV panels, maintenance mode using batteries - PV panels diesel generators). The stand-alone photovoltaic system (SAPV), that was finally proposed for supplying the shoreline electrode station on the Stachtoroi islet, consisted of $115 \mathrm{PVs}$ of type Sxp154Q by Solbian (suitable for shipbuilding use) with two SMA SUNNY TRIPOWER 10,000 TL inverters and two 110V SunLight gel RES 6 SOPzV 850 battery systems (one parallel branch-55 elements in series per system) with two respective GSA industries chargers for the typical 3\% interest rate. In addition, for reliability reasons, two back-up $25 \mathrm{kVA}$ diesel generator sets were installed with a fuel oil tank of 10001 each. The classical solution involves an MV feeder of $20 \mathrm{kV}$ of power supply with a $25 \mathrm{kVA}, 20 \mathrm{kV} / 400 \mathrm{~V}$ three-phase transformer for the off-site electrode station from the Greek distribution network by Aegina Island according to the guidelines by CIGRE [14, chapter 7]. If the SAPV system is also compared with the classical solution the proposed SAPV system is superior for all rates from $0 \%$ to $10 \%$ [8]. However, in [8] only one type of SOLBIAN PV panel was studied (the one with the lowest price in $€ / \mathrm{Wp}$ ) which is suitable for shipbuilding as the station is located next to the sea (5 to $10 \mathrm{~m}$ from the coast). Yet, it was considered whether it is acceptable to replace special purpose panels by general purpose panels with a shorter lifespan, as well as whether the use of PV panels of smaller size or higher cost in $€ / \mathrm{Wp}$ can lead to cheaper solutions overall due to better utilization of the space in which they are installed.

The above led to the problem formulation of the optimal configuration, both technically and economically, of a PV power plant from a set of commercially available PV panels and inverters for various levels of nominal power, considering interest rates and land cost. The latter is usually proportional to the area occupied by the PV plant. Especially when the building roof is used, as in the substation of Stachtorroi [8], the relevant function is more complex, because the cost may be zero for the immediate available area, but if terrace expansion through cantilever construction is required the cost is no longer zero but increases significantly.

This paper proposes a methodology for the overall evaluation of a PV plant in order to achieve the minimum cost for different nominal power levels and deflated interest rates, while satisfying both the necessary technical requirements (e.g., maximum number of PV panels per string due to their maximum operating voltage to ground in relation to the PV panel open circuit voltage, lifespan according to the certifications, etc.), and other various costs, such as electromechanical components installation and operating costs, land occupation costs (for the complex terrace case), the impact of the efficiency of the individual components of the PV plant on the generated electrical power. The determination of the optimal system is based on a large set of real commercial data of individual key components (PV panels and inverters) of different companies, which necessarily leads to the use of the exhaustive search method resulting in a reasonable computational time to the most economical solution. In section 2 the mathematical background of the problem is formulated, in section 3 the proposed methodology is presented, in section 4 the relevant simulation is performed and in section 5 the relevant conclusions are obtained.

\section{Problem Formulation}

The aim is to find the appropriate configuration of a photovoltaic power plant with fixed PV panels including the type and number of PV panels and inverters in order to minimize the equivalent annual cost for a specific deflated interest rate. A power range from a minimum $P_{\min }$ value to a maximum $P_{\max }$ value (e.g., from $100 \mathrm{~W}$ to $25 \mathrm{~kW}$ ) is examined, where for each power value $P$ all acceptable panel and converter combinations in terms of technical specifications are considered, the corresponding costs are calculated and the optimal configuration of the PV station with the minimum cost is determined.

It is noted that maintenance costs for safety and cleaning purposes (i.e., the technician's salary, washing water, etc.) are considered fixed for the limited power ranges under consideration and will not be taken into account at this stage.

\subsection{Solar panels database elements}

For each type of panel to be examined, the following data have been recorded: 
1. PV panel serial number which can serve as an identification number,

2. PV panel manufacturer's name,

3. type of PV panel based on the company,

4. nominal power $P_{\text {nom_PV }}$ for PV panel at Standard Test Conditions (STC): a cell temperature of $25^{\circ} \mathrm{C}$ and an irradiance of 1000 $\mathrm{W} / \mathrm{m}^{2}$ with air mass 1.5 and ASTM G173-03 standard spectrum,

5. maximum power point voltage $V_{M P P}$ in $\mathrm{V}$ at STC,

6. maximum power point current $I_{M P P}$ in $\mathrm{A}$ at STC,

7. open circuit voltage $V_{O C}$ in $\mathrm{V}$ at STC,

8. short circuit current $I_{S C}$ in A at STC,

9. PV panel length $\ell_{P V-x}$ in $\mathrm{mm}$,

10.PV panel width $\ell_{P V-y}$ in $\mathrm{mm}$,

11.PV panel height $\ell_{P V-z}$ in $\mathrm{mm}$,

12.PV panels total cost Cost $_{P V}$ in $€$ including purchase/supply costs, transport costs and $24 \%$ mark-up added tax (for construction in Greece) without any temporary discounts,

13.typical lifespan $T_{P V}$ in years. In the case of PV panels with a certificate of resistance to seawater (salt water), the typical lifespan is equal to twice the warranty years, otherwise equal to the years of warranty (most companies other than SOLBIAN explicitly state that they do not guarantee their materials in a marine environment),

14.maximum system voltage due to dielectric strength) $V_{\max _{-} P V}$ in $\mathrm{V}$ that can be applied to the panel,

15. maximum reverse current in $\mathrm{A}$.

\subsection{Solar inverters database elements}

For each type of direct current (DC) to alternating current (AC) inverter to be examined the following data have been recorded:

1. inverter serial number which can serve as an identification number,

2. inverter manufacturer's name,

3. type of inverter based on the company,

4. inverter's nominal input power $P_{\text {nom_INV }}$ in W,

5. maximum no-load DC input voltage / maximum operating DC input voltage to ground (due to dielectric strength) $V_{\text {max } I N V}$ in $\mathrm{V}$ that can be applied to the inverter,

6. minimum operating DC voltage of the maximum power point tracking algorithm $V_{M P P_{-} I N V_{-} \min }$ in $\mathrm{V}$,

7. maximum operating $\mathrm{DC}$ voltage of the maximum power point tracking algorithm $V_{M P P_{-} I N N_{-} \max }$ in $\mathrm{V}$,
8. nominal operating DC voltage $V_{\text {nom_INV }}$ in $\mathrm{V}$, which when not given, is computed from the mean value of the minimum operating DC voltage $V_{M P P_{-} I N V_{-} \min }$ and the maximum operating DC voltage $V_{M P P_{-} I N V_{-} \max }$ under the operating conditions of the maximum power point tracking algorithm,

9. minimum operating DC voltage inverter $V_{I N V_{-} \min }$ in $\mathrm{V}$,

10.initial DC voltage / inverter start-up voltage $V_{I N V_{-} \text {start }}$ in $\mathrm{V}$, which is greater than or equal to the minimum inverter operating DC voltage $V_{I N V_{-} \text {minn }}$, as it corresponds to open-circuit conditions,

11.maximum operating DC current per input of maximum power point tracking algorithm $I_{\text {nom_INV }}$ in A, where in the case of multiple strings with different currents the lowest value shall be obtained,

12.maximum short-circuit DC current per input of maximum power point tracking algorithm $I_{S C_{-} I N V}$ in $\mathrm{A}$, where in the case of multiple strings with different currents the lowest value shall be obtained,

13. number of inputs $N_{\text {INV_inputs }}$ of maximum power point tracking algorithm,

14.number of strings per input of maximum power point tracking algorithm $N_{\text {INV_strings_per_input, }}$ set equal to the unit when not specified,

15.inverters total cost $\operatorname{Cost}_{I N V}$ in $€$ including purchase/supply cost, transport cost and purchase added tax with a $24 \%$ mark-up rate (for construction in Greece) without any temporary discounts,

16.typical lifespan $T_{I N V}$ in years, which is equal to the warranty years plus 5 years for all companies,

17.typical efficiency $\eta_{I N V}$ according to European standards,

18.number of inverter phases entering 1 or 3 respectively for single- or three-phase,

19.nominal alternating voltage $V_{\text {nom_INV_AC }}$ in $\mathrm{V}$, which is $230 \mathrm{~V}$ for single-phase inverters and $400 \mathrm{~V}$ for three-phase inverters,

20.nominal alternating voltage frequency $f_{\text {nom_INV }}$ in $\mathrm{Hz}$, which is $50 \mathrm{~Hz}$ due to the specific power system,

21.lower limit of the inductive power factor, which must be 0.8 or less to meet the requirements of the power system concerned (inductive load factor ranges from 0.8 to 1 ),

22. lower limit of the capacitive power factor, which must be 0.8 or less to meet the requirements of the power system concerned (capacitive load factor ranges from 0.8 to 1 ). 
The other output components, such as power quality indices, do not need to be recorded on this study.

\subsection{Determination of manufacturing cost of main components of electromechanical equipment}

For each type of PV panel, based on the limits of the required power between $P_{\min }$ and $P_{\max }$, the respective minimum and maximum number of panels $N_{\text {min_PV }}$ and $N_{\text {max_ } P V}$ are calculated as follows:

$$
\begin{aligned}
& N_{\text {min_ } P V}=\left\lfloor\frac{P_{\min }}{P_{n o \mathrm{~m}_{-} P V}}\right\rfloor \\
& N_{\text {max } \_P V_{-}}=\left|\frac{P_{\max }}{P_{n o m_{-} P V}}\right|
\end{aligned}
$$

\subsubsection{Technical data determination for each combination of $P V$ panels and inverters}

For each inverter and each number of panels $N_{P V}$ within the limits $N_{\text {min_}} P V$ and $N_{\text {max_ } P V}$, the following points are examined:

1. The number of inverters to be installed. According to the inverter type, as, if it is singlephase then three or six, etc., should be installed, while if it is three-phase, then the number calculated should be placed, as the underconfiguration power system is a three-phase system.

2. The nominal alternating voltage level, which must be between 220 to $240 \mathrm{~V}$ in the case of single phase and between 380 to $420 \mathrm{~V}$ in the case of three phase.

3. The frequency level of the alternating voltage, which should be between 49.5 and $50.5 \mathrm{~Hz}$.

4. The power factor range at the inverter's output, which must cover the range from at least 0.8 inductive factor to 1 ohmic factor and from 0.8 capacitive factor to 1 ohmic factor (narrower range is not allowed).

5. If the resulting inverter is out of specification, another inverter is examined, otherwise the next step is followed.

6. For the specific inverter the maximum PV panel string size $N_{S}$ is calculated:

$$
N_{S}=\min \left\{\begin{array}{l}
\left\lfloor\frac{V_{\text {max }_{-} P V}}{1.15 \cdot V_{\text {OC }}}\right\rfloor,\left\lfloor\frac{\left.V_{\text {max }_{\text {IINV }}}\right\rfloor,}{1.15 \cdot V_{\text {OC }}}\right\rfloor \\
\left\lfloor\frac{V_{M P P_{-} I N V_{-} \max }}{V_{M P P}}\right\rfloor, \text { round }\left(\frac{V_{\text {nom_INV }}}{V_{M P P}}\right)
\end{array}\right\}
$$

Where on the right hand side of the equation the first term expresses the maximum integer number of elements as determined by the maximum PV panel system voltage with respect to the PV panel's open-circuit voltage (increased by a safety factor of $+15 \%$ due to, temperature variations, range of values during the industrial production process, etc.), the second term expresses the maximum integer number of elements determined by the maximum no-load DC input voltage of the inverter with respect to the PV panel opencircuit voltage (increased by the corresponding safety factor of $+15 \%$ ), the third term expresses the maximum integer number of elements due to the maximum operating DC voltage with respect to the nominal PV panel voltage under the operating conditions of the maximum power point tracking algorithm, the fourth term expresses the rounded integer number of elements due to the inverter's nominal operating DC voltage of the maximum power point tracking algorithm with respect to the nominal operating voltage of the PV panel under operating conditions of the maximum power point tracking algorithm. Eq. (3) requires a number greater than or equal to 1 , otherwise the inverter is out of the required specifications and another inverter is chosen, otherwise the next step follows.

7. The required number of PV strings $N_{\text {strings }}$ is calculated in order to configure the photovoltaic station with $N_{P V}$ number of panels:

$$
N_{\text {strings }}=\left|\frac{N_{P V}}{N_{S}}\right|
$$

That is, if the number $N_{P V}$ of PV panels is 65 and the maximum number of $N_{S}$ strings is 32 , then the necessary number of series is $65 / 32=$ 2.03125 , where rounding up results 3 .

8. Subsequently it is checked whether the minimum voltage level for the smooth operation of the maximum power point tracking algorithm is achieved by first calculating the minimum number $N_{\text {minPV_string }}$ of PV panels in a string as follows:

$$
N_{\text {minPV_string }}=\left\lfloor\frac{N_{P V}}{N_{\text {strings }}}\right\rfloor
$$

That is, if the number $N_{P V}$ of PV panels is 65 and the required number $N_{\text {strings }}$ of strings is 3 , then the minimum number $N_{\text {min } P V_{-} \text {string }}$ of panels 
in a string is $65 / 3=21.6667$, where rounding down results to 21 . It is then checked whether the operating voltage condition is met, where the minimum nominal DC voltage $V_{M P P_{-} I N V_{-} \text {min }}$ of the maximum power point tracking algorithm must be smaller than the voltage generated by the minimum number $N_{\text {min } P V_{-} \text {string }}$ of PV panels per string operating at nominal voltage under the maximum power conditions $V_{M P P}$ at STC.

$$
V_{M P P_{-} I N V_{-} \min } \leq N_{\text {minPV_string }} \cdot V_{M P P}
$$

If eq. (6) is not met, the inverter is out of specification and another inverter is chosen, otherwise the next step is taken.

9. Following, the produced currents per inverter input, operating the maximum power point tracking algorithm, are checked. In particular, the maximum number $N_{P V \text { max_strings_inputINV }}$ of parallel strings per input of maximum power point tracking algorithm is calculated in relation to the PV panel's maximum power point current, the PV panel's short circuit current and the number of strings per input of the maximum power point tracking algorithm from side of the inverter's manufacturer:

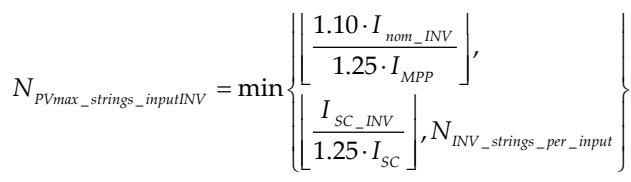

Where on the right hand side of the equation the first term expresses the maximum integer number of PV strings per input as determined by the maximum operating DC current $I_{\text {nom_INV }}$ of the inverter per input of the maximum power point tracking algorithm (increased by $10 \%$ for transient charge conditions) with respect to the nominal current of the PV panel at maximum power conditions $I_{M P P}$ (increased by a safety factor of $+25 \%$ due to, temperature variations, range of values during the industrial production process, etc.), the second term expresses the maximum integer number of PV strings per input as determined by the maximum short circuit DC current $I_{S C_{-} I N V}$ of the inverter per input of maximum power point tracking algorithm (without any increments, as the phenomenon is already transient) with respect to the short-circuit current $I_{S C}$ of the PV panel (increased by the corresponding safety factor of $+25 \%$ due to manufacturing and temperature variations), the third term is the maximum integer number of PV strings per input and it cannot exceed the number of PV strings per input $N_{I N V_{-} \text {strings_per_input }}$ of the maximum power point tracking algorithm as given by the manufacturer. Eq. (7) requires a value greater than or equal to 1 , otherwise the inverter is out of the required specifications and another inverter is chosen, otherwise the next step follows.

10.If the inverter is three-phase, then the required number of inverters $N_{I N V}$ is calculated as the maximum between the quotient of the required number of PV strings $N_{\text {strings }}$ to the total number of available strings per inverter given by the product of the maximum number of parallel strings per input of the maximum power point tracking algorithm $N_{P V \text { max_strings_inputINV }}$ and the number of inputs of the maximum power point tracking algorithm $N_{I N V_{i} i n p u t s}$ on the part of the inverter manufacturer, and the quotient of the nominal power of all $\mathrm{PV}$ panels $N_{P V} P_{\text {nom_ } P V}$ to the nominal power of the inverter $P_{\text {nom_INV: }}$

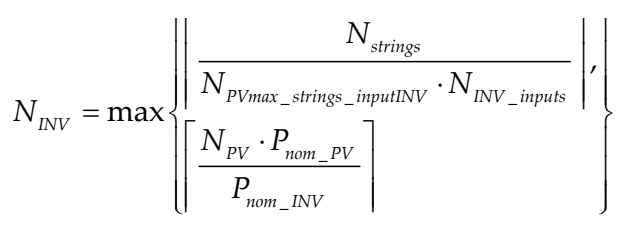

If there is a requirement for an increased level of reliability, then the required number of three-phase inverters $N_{I N V}$ cannot be less than 2 . If the inverter is single-phase, to form a threephase network one inverter per phase is required, so the number of inverters should be a multiple of 3, which is achieved as follows:

$$
N_{I N V}=3 \cdot\left|\frac{N_{I N V}}{3}\right|
$$

If there is a requirement of increased reliability level, then the necessary number of singlephase inverters $N_{I N V}$ cannot be less than 6 .

\subsubsection{Equivalent annual cost of installing and operating inverters}

The annual equivalent cost of installing and operating the inverter in question is calculated as follows:

1. Calculation of the capital recovery factor for a specific deflated rate $i$ and typical inverter lifespan $T_{I N V}$ as follows: 


$$
C R F_{I N V}=\left\{\begin{array}{cc}
\frac{1}{T_{I N V}}, & i=0 \\
\frac{i \cdot(1+i)^{T_{I N V}}}{(1+i)^{T_{I N V}}-1}, & i \neq 0
\end{array}\right.
$$

2. Calculation of the annual equivalent cost of construction and operation of the inverter as follows:

$$
\operatorname{Cost}_{\text {INVeq }}=\left\{\begin{array}{l}
C R F_{I N V} \cdot N_{I N V} \cdot \operatorname{Cost}_{I N V} \\
+\left(1-\eta_{I N V}\right) \cdot E_{\text {ideal__PV }} \cdot \mathrm{c}_{n o_{\text {_sup }} l y}
\end{array}\right.
$$

Where the first term concerns the annual depreciation of inverter supply capital for the required number of inverters $N_{I N V}$ at a cost of Cost $_{I N V}$ per unit, the second term refers to the cost of energy lost from the ideally produced energy by the PV panels $E_{\text {ideal_PV }}$ due to the efficiency of the inverter $\eta_{I N V}$ with an indicative cost of energy loss per $\mathrm{kWh}$ equal to $c_{n o \_s u p p l y}$, in order to take into account the inverter efficiency (i.e., between two inverters with similar cost and lifespan to prefer the one with the best efficiency).

The calculation of the ideally produced energy by the PV panels $E_{\text {ideal_PV }}$ is done as follows: Let it be a typical day of the year that is taken to be the spring or autumnal equinox, during which the solar radiation on a surface of the earth without the mediation of clouds, shading, etc. varies sinusoidally between the hours of 06:00 and 18:00, so with a constant degree of efficiency of the PV panels and ignoring the starting voltage required for the operation of the inverters the corresponding power produced by the PV panels of number $N_{P V}$ and nominal power $P_{\text {nom_ } P V}$ during the day also varies sinusoidally as follows:

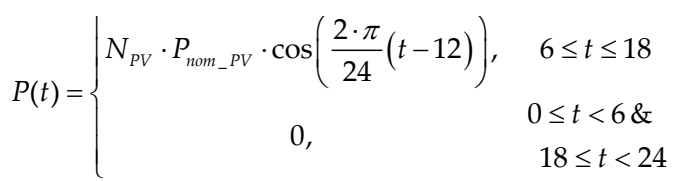

So, the ideal daily energy is equal to:

$$
\begin{gathered}
E_{\text {ideal_day }}=\int_{0}^{24} P(t) \cdot d t=\int_{6}^{18} N_{P V} \cdot P_{\text {nom_ } P V} \cdot \cos \left(\frac{2 \cdot \pi}{24}(t-12)\right) \cdot d t \\
\Rightarrow E_{\text {iddal_day }}=\left.\frac{N_{P V} \cdot P_{\text {nom_ } P V}}{\frac{2 \cdot \pi}{24}} \cdot \sin \left(\frac{2 \cdot \pi}{24}(t-12)\right)\right|_{6} ^{18} \Rightarrow
\end{gathered}
$$

$$
E_{i d e a l \_ \text {day }}=\frac{N_{P V} \cdot P_{n o m_{-} P V}}{\frac{2 \cdot \pi}{24}} \cdot 2=N_{P V} \cdot P_{n o m_{-} P V} \cdot \frac{24}{\pi}
$$

The corresponding average ideal power is equal to:

$$
P_{\text {ideal }}=\frac{E_{\text {ideal_day }}}{24}=N_{P V} \cdot P_{\text {nom_- } P V} \cdot \frac{1}{\pi}
$$

Therefore, the average annual ideal energy produced by the PVpanels is equal to:

$$
E_{\text {ideal_PV }}=P_{\text {ideal }} \cdot 8760[\mathrm{~h}]=\frac{8.76}{\pi} \cdot N_{P V} \cdot P_{\text {nom_ } P V}[\mathrm{kWh}]
$$

For the calculation of the indicative energy loss cost per $\mathrm{kWh}$, a typical $20 \mathrm{~kW}$ diesel generator is considered [8], which follows the consumption curve:

$$
\text { fuel }\left[\frac{\mathrm{kg}}{h}\right]=\left\{\begin{array}{l}
6 \cdot 10^{-4} \cdot\left(\frac{P_{g}[k W]}{20}\right)^{2}+ \\
4.2833 \cdot\left(\frac{P_{g}[k W]}{20}\right)+0.7874
\end{array}\right.
$$

Which is obtained by applying the least squares method to the data of [15] for different values of generator output power $P_{g}$. At its optimum operating point, it produces $20 \mathrm{kWh}$ with an oil consumption of $5.0707 \mathrm{~kg} / \mathrm{h}$, i.e., 0.253535 $\mathrm{kg} / \mathrm{kWh}$. Considering that in Greece the cost of diesel is $1.35 € / 1$ and with a typical density of $0.832 \mathrm{~kg} / \mathrm{l}$ it appears that the minimum energy cost is $0.411 € / \mathrm{kWh}$, so the typical cost of energy loss $c_{n o \_s u p p l y}$ is taken equal to 0.42 $€ / \mathrm{kWh}$.

3. After all the inverters are examined for each possible number of PV panels $N_{P V}$, the one that gives the lowest value of construction and operation costs from eq. (11) is chosen along with the corresponding number of panels.

\subsubsection{Equivalent annual cost of installing PV panels}

Regarding the annual equivalent installation cost of PV panels, the capital recovery rate for a specific deflated interest rate $i$ and typical panel lifespan $T_{P V}$ is initially determined as follows: 


$$
C R F_{P V}=\left\{\begin{array}{cc}
\frac{1}{T_{P V}}, & i=0 \\
\frac{i \cdot(1+i)^{T_{P V}}}{(1+i)^{T_{P V}}-1}, & i \neq 0
\end{array}\right.
$$

So, the annual equivalent cost of PV panels construction Cost $_{P V e q}$ based on the number of panels $N_{P V}$ and the PV panel cost $\operatorname{Cost}_{P V}$ per panel is equal to:

$$
\operatorname{Cost}_{P V e q}=C R F_{P V} \cdot N_{P V} \cdot \operatorname{Cost}_{P V}
$$

\subsection{4 "Land occupation" equivalent annual cost} In cases such as the present, where the PV panels are placed on the roof of a building, in order to determine the cost of "land occupation", it is necessary to first calculate the maximum number of panels that can be placed on the roof in question, according to its dimensions. In particular, suppose that the length and width of each PV panel are $\ell_{P V-x}$ and $\ell_{P V-y}$ respectively and that the panels are placed on a roof of dimensions $L_{X}$ and $L_{Y}$ along the $\mathrm{xOx}$ and $\mathrm{yOy}^{\prime}$ axes, without additional inclination or slope support frame. In addition, there are aisles of width $d_{X}$ and $d_{Y}$ along the $\mathrm{xOx}$ and yOy' axes (with a width of $0.40 \mathrm{~m}$ ), while in order to allow human access over the panels between two aisles, the maximum allowed length is $\ell_{p e r}$ (with a value of $2.00 \mathrm{~m}$ ), as shown in Fig. 1.

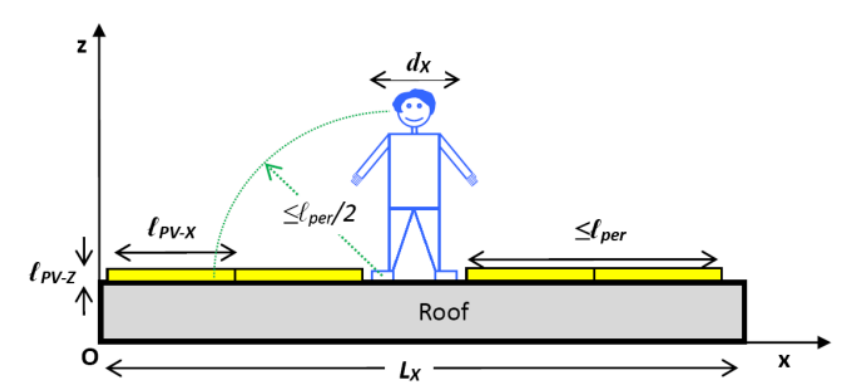

Fig. 1. Roof section with PV panels placed along the $\mathrm{xOx}^{\prime}$ axis, indicating minimum aisle distances and maximum permissible lengths of the PV panel groups, under formation on the roof.

So, the panels can be placed on the terrace in the following ways, as shown in Fig. 2:

- mounting a panel with the length $\ell_{P V-x}$ along the $\mathrm{xOx}$ ' axis, so that the width of $\ell_{P V-y}$ is along the yOy' axis,

- mounting a panel with the width $\ell_{P V-y}$ along the $\mathrm{xOx}$ ' axis, so that the length of $\ell_{P V-x}$ is along the yOy' axis.

Intermediate placements, i.e., at an angle to the Oxy level of the terrace, are not implemented, because they generally give worse results (fewer panels), while it is considered that the terrace is already oriented on the north-south axis [8].

Initially, the number of panels $n_{P V-x}$ that can be placed between two aisles is determined, if the panels are joined lengthwise $\ell_{P V-x}$ and if there is an aisle along the corresponding axis that they are placed, which is equal to:

$$
n_{P V-x}=\left\lfloor\frac{\ell_{p e r}}{\ell_{P V-x}}\right\rfloor
$$

Respectively, the number of panels $n_{P V-y}$ that can be placed between two aisles is determined, if the panels are joined width wise $\ell_{P V-y}$, and if there is an aisle along the corresponding axis that they are placed, which is equal to:

$$
n_{P V-y}=\left\lfloor\frac{\ell_{p e r}}{\ell_{P V-y}}\right\rfloor
$$

If the panels are placed with their length $\ell_{P V-x}$ along the $\mathrm{xOx}$ ' axis and there is no aisle, i.e., theoretically the aisle has zero width (practically for $d_{X}<0.001 \mathrm{~m}$ ), then the total number of panels $n_{\text {tot } x}$ is equal to:

$$
n_{\text {tot-x }}=\left\lfloor\frac{L_{X}}{\ell_{P V-x}}\right\rfloor
$$

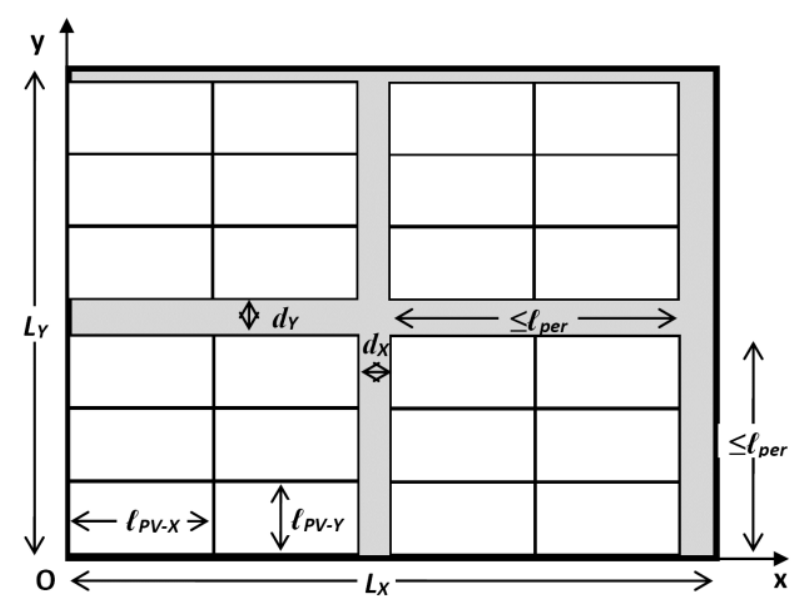

(a) 


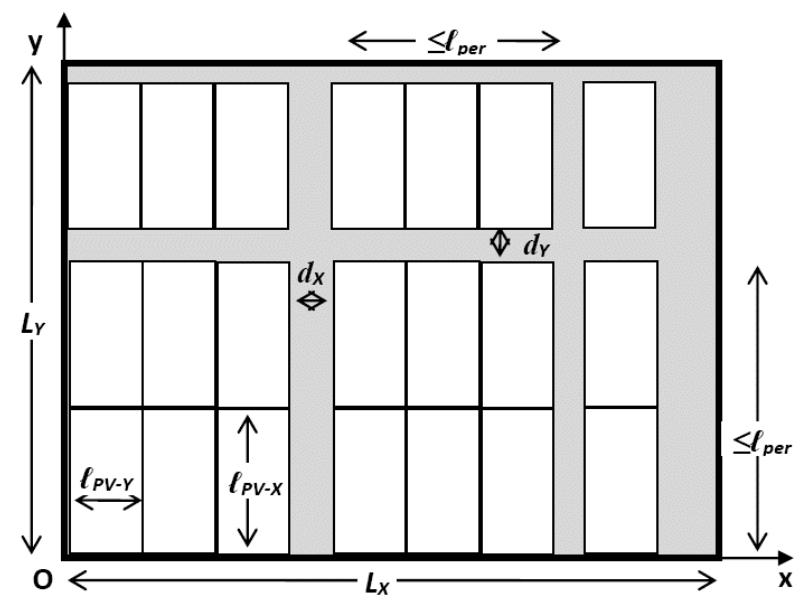

(b)

Fig. 2. Panel placement on a roof plan: (a) panel length $\ell_{P V-x}$ along the $\mathrm{xOx}$ ' axis and width $\ell_{P V-y}$ along the yOy' axis, (b) panel width $\ell_{P V-y}$ along the xOx' axis and length $\ell_{P V-x}$ along the yOy' axis, indicating minimum aisle distances and maximum permissible lengths of the PV panel groups, under formation on the roof.

If the panels are placed with their length $\ell_{P V-x}$ along the $\mathrm{xOx}$ ' axis and there is an aisle with width $d_{X}$, then according to Fig. 3 the number of panel groups $n_{\text {team-x } x}$ that fit along the length $L_{X}$ is determined as follows:

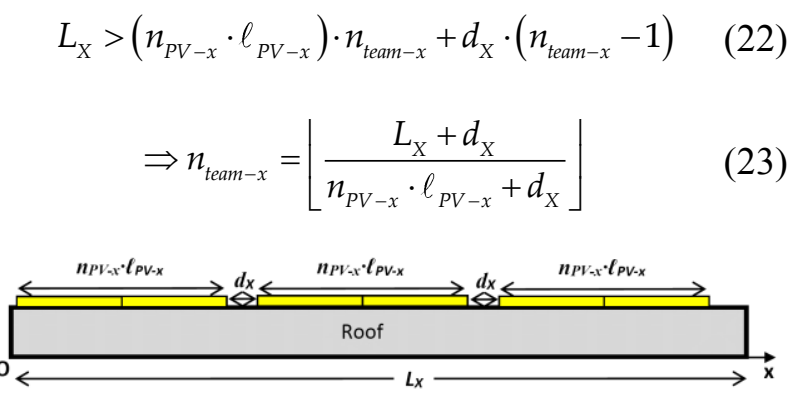

Fig. 3. Rooftop section with the panels placed with their length $\ell_{P V-x}$ along the $\mathrm{xOx}$ ' axis, with aisles of $d_{X}$ width and with $n_{\text {team-x }}$ number of panel groups to be determined $\left(n_{\text {team }-x}=3, n_{P V-X}=2\right)$.

Possibly, an additional aisle of width $d_{X}$ and an additional number of panels $\Delta n_{X}$ smaller than $n_{P V-x}$ may be also installed along the $\mathrm{xOx}$ ' axis. To examine this possibility, the remaining length left by the panel groups and the respective aisles must be calculated, as shown in Fig. 4:

$$
\Delta L_{X}=L_{X}-n_{\text {team }-x} \cdot\left(n_{P V-x} \cdot \ell_{P V-x}+d_{X}\right)
$$

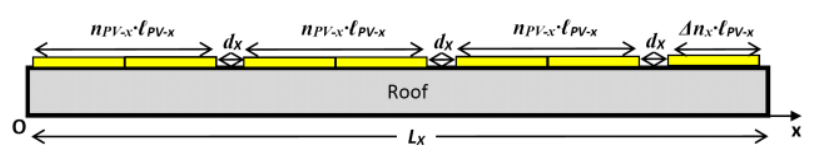

Fig. 4. Roof section with the panels placed with their length $\ell_{P V-x}$ along the xOx' axis, with aisles of $d_{X}$ width and with $n_{\text {team-x }}$ number of panel groups and with additional number of panels $\Delta n_{X}$ to be determined ( $n_{\text {team }}$. $\left.{ }_{x}=3, n_{P V-X}=2, \Delta n_{X}=1\right)$.

If the remaining length is greater than zero, then the additional number of panels $\Delta n_{X}$ equals:

$$
\Delta n_{X}=\left\lfloor\frac{\Delta L_{X}}{\ell_{P V-x}}\right\rfloor
$$

So, the total number of panels $n_{\text {tot- } X}$ at $\mathrm{xOx}$ ' is equal to:

$$
n_{\text {tot }-X}=n_{\text {team }-x} \cdot n_{P V-x}+\Delta n_{X}
$$

If the panels are placed with their width $\ell_{P V-y}$ along the yOy' axis and there is no aisle, i.e., theoretically the aisle has zero width (practically for $d_{Y}<0.001 \mathrm{~m}$ ), then the total number of panels $n_{\text {tot- } y}$ is equal to:

$$
n_{\text {tot-y }}=\left\lfloor\frac{L_{Y}}{\ell_{P V-y}}\right\rfloor
$$

If the panels are placed with their length $\ell_{P V-y}$ along the yOy' axis and there is an aisle with width $d_{y}$, then the number of panel groups $n_{\text {team-y }}$ that fit along the length $L_{y}$ is determined similarly to the $\mathrm{xOx}$ ' axis:

$$
n_{\text {team }-Y}=\left\lfloor\frac{L_{Y}+d_{Y}}{n_{P V-y} \cdot \ell_{P V-y}+d_{Y}}\right\rfloor
$$

Possibly, an additional aisle of width $d_{Y}$ and an additional number of panels $\Delta n_{Y}$ smaller than $n_{P V-Y}$ may be also installed along the yOy' axis. To examine this possibility, the remaining length left by the panel groups and the respective aisles must be calculated, similarly to the previous $\mathrm{xOx}$ ' analysis:

$$
\Delta L_{Y}=L_{Y}-n_{\text {team }-y} \cdot\left(n_{P V-y} \cdot \ell_{P V-y}+d_{Y}\right)
$$

If the remaining length is greater than zero, then the additional number of $\Delta n_{Y}$ panels equals:

$$
\Delta n_{Y}=\left\lfloor\frac{\Delta L_{Y}}{\ell_{P V-y}}\right\rfloor
$$

So, the total number of panels $n_{\text {tot-Y }}$ at yOy' is equal to:

$$
n_{\text {tot }-y}=n_{\text {team }-y} \cdot n_{P V-y}+\Delta n_{Y}
$$


Therefore, the total number of panels $n_{t o t}$ on the surface of the roof is equal to:

$$
n_{\text {tot }}=n_{\text {tot }-x} \cdot n_{\text {tot }-y}
$$

Likewise, one can consider the case of rotating the panels with respect to the directions, i.e., the panels are placed with their width $\ell_{P V-y}$ along the xOx' axis and with their length $\ell_{P V-x}$ along the yOy' axis.

The following four combinations are considered in this case:

- the panels are placed with their length $\ell_{P V-x}$ along the xOx' axis and with their width $\ell_{P V-y}$ along the yOy' axis, with only one aisle along the $\mathrm{xOx}^{\prime}$ axis,

- the panels are placed with their length $\ell_{P V-x}$ along the $\mathrm{xOx}$ ' axis and with their width $\ell_{P V-y}$ along the yOy' axis, with only one aisle along the yOy' axis,

- the panels are placed with their width $\ell_{P V-y}$ along the $\mathrm{xOx}$ ' axis and with their length $\ell_{P V-x}$ along the yOy' axis, with only one aisle along the $\mathrm{xOx}^{\prime}$ axis,

- the panels are placed with their width $\ell_{P V-y}$ along the $\mathrm{xOx}^{\prime}$ axis and with their length $\ell_{P V-x}$ along the yOy' axis, with only one aisle along the yOy' axis.

From the four combinations, the one that according to eq. (32) gives the largest number of panels is selected in each case. It is also possible that the required number of panels may not fit in the initial dimensions of the terrace $L_{X-i n}$ and $L_{Y-i n}$ along the $\mathrm{xOx}$ 'and $\mathrm{yOy}$ ' axes respectively. In this case the dimensions of the terrace $L_{X}$ and $L_{Y}$ can be altered from $L_{X-i n}$ and $L_{Y-i n}$ to $\left(L_{X-i n}+\Delta L_{X}\right)$ and $\left(L_{Y-i n}+\Delta L_{Y}\right)$ respectively with a step $\Delta \ell_{\text {step }}$. For the present case of the small building of Stachtorroi the respective values are [8]: roof plan dimensions $L_{X-i n}=13.30 \mathrm{~m}$, $L_{Y-i n}=7.60 \mathrm{~m}$, maximum cantilever width $\Delta L_{X}=$ $\Delta L_{Y}=4.00 \mathrm{~m}$ (for techno-economic reasons, a cantilever of more than $2.00 \mathrm{~m}$ cannot be constructed and the cantilever of the terrace extends symmetrically on both sides) and $\Delta \ell_{\text {step }}=0.10 \mathrm{~m}$ (in concrete constructions the best accuracy is $5 \mathrm{~cm}$, so with extension to both ends it becomes $2 * 5 \mathrm{~cm}=10$ $\mathrm{cm})$. For the first meter of cantilever around the roof, the cost of extension amounts to $c_{\text {roof- }-1}$ (indicatively at $225 € / \mathrm{m}^{2}$ ) and for the next meter the cost amounts to $c_{\text {roof-2 }}$ (indicatively at $300 € / \mathrm{m}^{2}$ ), as a more reinforced construction is required. For zone 1, i.e., when the dimensions of the roof are from $L_{X}$ in $* L_{Y-\text { in }}$ to $\left(L_{X-\text {-in }}+\Delta L_{X-l i m l}\right) *\left(L_{Y-i n}+\Delta L_{Y-\text {-liml }}\right)$, the additional lengths within it are determined as follows:

$$
\begin{aligned}
& \Delta L_{X-1}=\min \left\{\max \left\{0,\left(L_{X}-L_{X-i n}\right)\right\}, \Delta L_{X-l i m 1}\right\} \\
& \Delta L_{Y-1}=\min \left\{\max \left\{0,\left(L_{Y}-L_{Y-i n}\right)\right\}, \Delta L_{Y-l i m 1}\right\}
\end{aligned}
$$

where the first terms on the right-hand side of eq. (33) and (34) determine whether an extension has been made and therefore is in zone 1 and the second terms determine the maximum limits of zone 1 , as shown in Fig. 5.

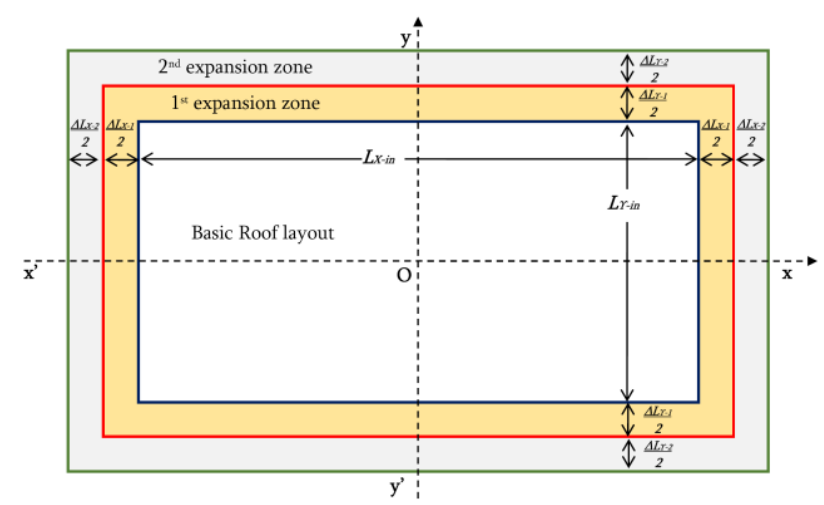

Fig. 5. Roof plan with two extension zones ("1" and "2") achieved with cantilevers.

So, the area of zone 1 is equal to:

$$
E_{\text {AREA-1 }}=\left\{\begin{array}{l}
\Delta L_{X-1} \cdot L_{Y-i n}+\Delta L_{Y-1} \cdot L_{X-i n} \\
+\Delta L_{X-1} \cdot \Delta L_{Y-1}
\end{array}\right.
$$

For zone 2, the corresponding additional lengths within it shall be determined as follows:

$$
\begin{aligned}
& \Delta L_{X-2}=\max \left\{0,\left(L_{X}-\Delta L_{X-l i m 1}\right)\right\} \\
& \Delta L_{Y-2}=\max \left\{0,\left(L_{Y}-\Delta L_{Y-l i m 1}\right)\right\}
\end{aligned}
$$

Where the terms on the right-hand side of eq. (36) and (37) determine whether an extension has been made and therefore is in zone 2. Unlike eq. (33) and (34) there is no other term, as the dimensions cannot exceed the dimensions $\left(L_{X-i n}+\Delta L_{X}\right)$ and $\left(L_{Y-i n}+\Delta L_{Y}\right)$ respectively. In which case the area of zone 2 shall be equal to:

$$
E_{A R E A-2}=\left\{\begin{array}{l}
\Delta L_{X-2} \cdot\left(L_{Y-i n}+\Delta L_{Y-l i m 1}\right) \\
+\Delta L_{Y-2} \cdot\left(L_{X-i n}+\Delta L_{X-l i m 1}\right) \\
+\Delta L_{X-2} \cdot \Delta L_{Y-2}
\end{array}\right.
$$

It is then possible to calculate the roof occupation/expansion cost from the side of the PV panels as follows:

$$
\text { Cost }_{\text {roof }}=c_{\text {roof }-1} \cdot E_{\text {AREA-1 }}+c_{\text {roof }-2} \cdot E_{\text {AREA-2 }}
$$


Following, the capital recovery rate can be calculated for a specific deflated interest rate $i$ and typical roof lifespan $T_{\text {roof }}$ (typical duration 25 years) as follows:

$$
C R F_{\text {roof }}=\left\{\begin{array}{cc}
\frac{1}{T_{\text {roof }}}, & i=0 \\
\frac{i \cdot(1+i)^{T_{\text {rof }}}}{(1+i)^{T_{\text {rof }}}-1}, & i \neq 0
\end{array}\right.
$$

So, the annual equivalent cost of constructing the roof extension Cost roof-eq is equal to:

$$
\operatorname{Cost}_{\text {roof-eq }}=C R F_{\text {roof }} \cdot \text { Cost }_{\text {roof }}
$$

Then, for each possible number of panels $N_{P V}$, the roof dimensions that fit the panels are found, and from all the accepted dimensions, those with the lowest annual equivalent cost are selected. If no dimensions are appropriate, the solution is discarded, and the algorithm goes to the next step.

\subsubsection{Total equivalent annual cost of PV plant}

Then, the total cost for the number $N_{P V}$ of panels of specific nominal power according to the panel type is determined by choosing the most economical inverter and rooftop size as follows:

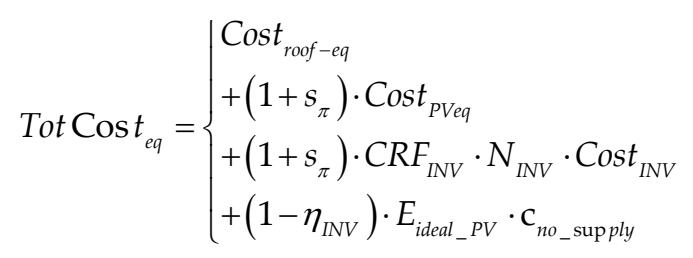

Where $s_{\pi}$ is a scaling factor of $10 \%$ on the cost of supplying PV panels and inverters for the electrical connections, while the latter term serves as a "penalty term" for the energy lost from the ideally generated energy by the PV panels due to the inverter's efficiency.

Finally, for each type of PV panel, the annual equivalent cost curve is levelized per regular power steps $P_{\text {step }}$ (indicative of $100 \mathrm{~W}$ ), where in this case, for each power value the installation cost and other technical characteristics of the photovoltaic power station chosen is the one that marginally covers the required power, as shown in Fig. 6. The levelized cost curves of the different types of PV panels are then compared and the cheapest solution is selected for each power level per interest rate. It is not possible to compare the actual cost curves for different types of panels due to the different nominal powers per panel.

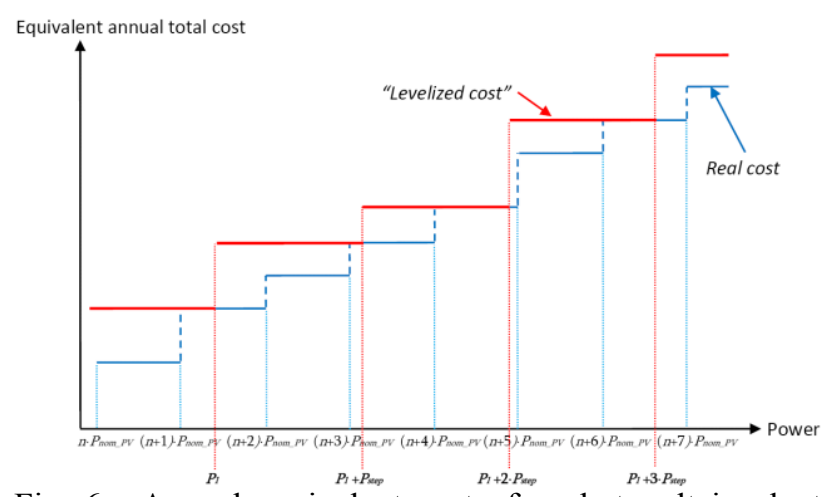

Fig. 6. Annual equivalent cost of a photovoltaic plant with respect to nominal power (blue line $=$ actual, red $=$ levelized).

\section{Proposed Methodology}

Based on the above, the steps of the proposed methodology are:

1. The actual data for the PV panels and inverters that are available from commercial companies are entered, as well as the ranges and steps of change of the deflated interest rate and the nominal power of the PV plant under construction.

2. The current interest rate is defined through an appropriate loop statement.

3. For each type of PV panel, eq. (1) and (2) determine the range of the number of panels.

4. For each possible number of panels all available inverters are examined as follows:

i. The technical characteristics are checked according to subsection 2.3.1, the PV plant is configured by calculating the number of PV panels per string, as well as the number of strings and inverters according to eq. (3) to (9).

ii. If the use of the inverter in question is possible based on the technical specifications, the cost of its installation and operation is calculated according to eq. (10) to (16).

iii. From the set of inverters that satisfy the technical specifications, the one with the lowest installation and operation costs is determined.

Then the equivalent cost of installing PV panels is determined through eq. (17) and (18), the equivalent cost of occupying land through eq. (19) to (41), and the total equivalent annual cost of the PV plant through eq. (42).

5. Taking into account, for the type of PV panel under consideration, all possible values of the number of PV panels, the total curve of the annual equivalent PV plant cost for the power 
range considered is formed, which is levelled at appropriate power steps according to Figure 6 .

6. Steps 3 to 5 are repeated for all types of PV panels and the total curve of the minimum annual equivalent PV plant cost is determined from all the PV panel types, where each power step can correspond to a different type of panel - inverter - PV plant configuration, as well as roof extension.

7. Steps 2 to 6 are repeated for all interest rates considered, thereby implementing a sensitivity analysis of the solutions proposed.

Basically, due to the use of real data regarding the PV panels, the inverters and the extension of the roof, the method of exhaustive search is applied.

\section{Application of the Proposed Methodology}

The proposed methodology will be applied for the autonomous supply power system of the shoreline electrode substation on the Stachtorroi islet of Attica, as described in the introduction.

The input data include:

- 133 types of panels of the following companies: SOLBIAN [16], LG, REC, BenQ, Sharp, Trina, Panasonic, Axitec, Luxor, SunPower, Victron [17],

- 205 types of inverters of the companies: SMA, Fronius, Kaco, Kostal, Sungrow, Solax, Huawei, ABB, Goodwe, DELTA [18]. Some types have been excluded that require a particular kind of battery, or that contain an integrated charger (due to the specific requirements of the existing arrangement in Stachtoroi), or that have separate inverters and DC-to-DC converters with optimum power generation devices (which depending on the type of installation require a different combination of inverter and DC-to-DC converter per set of installed PV panels), such as SolarEdge company.

27,625 combinations of PV panel types and inverter types are practically examined and if the different interest rate levels are considered (from $0 \%$ to $10 \%$ with a step of $0.5 \%$ ) they amount to 572,565 different financial evaluations. Due to the special configuration of the electrical installation of the autonomous system, increased levels of reliability are required (i.e., at least two inverters are needed, etc.), and the types of PV panels and their number are determined, the types of inverters and their number are determined, extension dimensions of the roof and the total annual equivalent cost are determined.
Regarding the selection of the panel type, the following types emerge according to the corresponding results of Fig. 7, which has the threedimensional chart of the panel types in relation to the nominal power of the PV plant and the deflated capital recovery interest rate:

- $\mathrm{S} / \mathrm{N}=46$, type $=$ ND-BA385 of SHARP company with nominal power $385 \mathrm{~W}$,

- $\mathrm{S} / \mathrm{N}=50$, type $=\mathrm{ND}-\mathrm{AF} 330 \mathrm{C}$ of SHARP company with nominal power $330 \mathrm{~W}$,

- $\mathrm{S} / \mathrm{N}=55$, type $=$ HoneyM TSM335DE06M.08(II) of Trina company with nominal power $335 \mathrm{~W}$,

- $\mathrm{S} / \mathrm{N}=56$, type $=$ HoneyM TSM330DE06M.08(II) of Trina company with nominal power $330 \mathrm{~W}$,

- $\mathrm{S} / \mathrm{N}=58$, type $=$ Honey $\mathrm{M}+$ TSM310DD05A.08(II) of Trina company with nominal power $310 \mathrm{~W}$,

- $\mathrm{S} / \mathrm{N}=59$, type $=$ Honey $\mathrm{TSM}-285 \mathrm{PE} 06 \mathrm{H}$ of Trina company with nominal power $285 \mathrm{~W}$,

- $\mathrm{S} / \mathrm{N}=61$, type $=$ HoneyM TSM340DE06M.08(II) of Trina company with nominal power $340 \mathrm{~W}$,

- $\mathrm{S} / \mathrm{N}=69$, type $=$ Axitec AXIpremium AC300M/156-60S of Axitec company with nominal power $330 \mathrm{~W}$,

- $\mathrm{S} / \mathrm{N}=95$, type $=$ ECO LINE HALF-CELLS P120/280W of LUXOR company with nominal power $280 \mathrm{~W}$.

The corresponding study shows the overwhelming dominance of the photovoltaic panel with $\mathrm{S} / \mathrm{N} 95$ type ECO LINE HALF-CELLS P120 / $280 \mathrm{~W}$ of the LUXOR company with a nominal power of $280 \mathrm{~W}$ for powers up to $20 \mathrm{~kW}$ and higher prices for small interest rates up to $3 \%$ at $75.1 \%$ of the cases examined, as recorded in Table 1. This is due to its low cost, high power, despite its replacement in 5 years. There is also a slight variation in the PV panel choice for the same power depending on the interest rates, which is due to marginal variations resulting from the participation of the ideal energy of the PV panel and the inverter's different technical specifications according to the PV panel that leads to small variations of the respective annual equivalent cost and the corresponding selection. At the same time, it is observed that PV panels of large geometric dimensions and high nominal power are selected, displacing the SOLBIAN panels, which are specialized for shipbuilding applications and with a 5 -year warranty in salt environment, while the other panels under these conditions have zero warranty.

Regarding the selection of the number of panels of each PV panel type, there is an increasing trend of 
the number of panels used as the nominal power of the PV plant increases, as shown in Fig. 8. The difference in prices per interest rate is due solely to the change of the PV panel type.

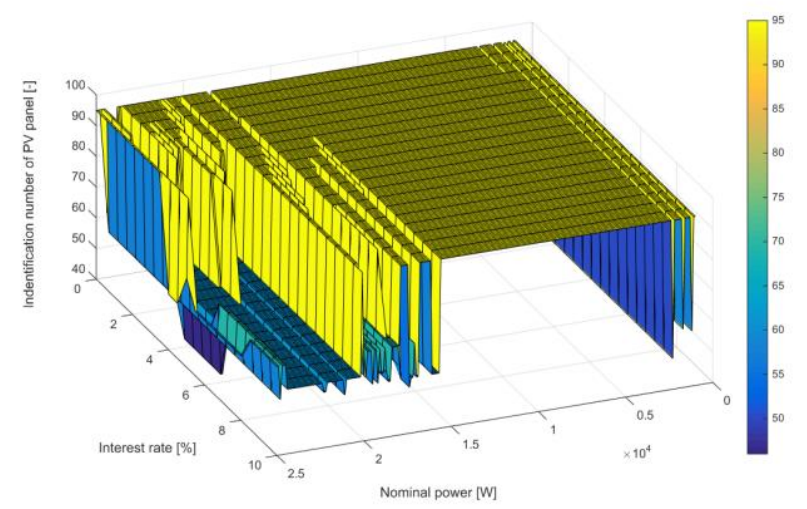

serial number in relation to the nominal power of the PV plant under configuration and the capital recovery interest rate, with increased reliability requirements for the set of 133 PV panels.

Fig. 7. Three-dimensional graph of the PV panel type

Table 1: Number of occurrences and percentage optimal selection of the PV panel type in terms of annual equivalent costs for various deflated interest rates for the 133 types of photovoltaic panels.

\begin{tabular}{|c|c|c|c|c|c|c|c|c|c|c|}
\hline \multirow{2}{*}{$\begin{array}{l}\text { Number of cases } \\
\text { Interest rate }[\%]\end{array}$} & \multicolumn{10}{|c|}{ Serial number of photovoltaic panel type } \\
\hline & 46 & 50 & 55 & 56 & 58 & 59 & 61 & 69 & 95 & Rest cases \\
\hline 0.0 & 0 & 1 & 0 & 0 & 5 & 1 & 6 & 0 & 228 & 0 \\
\hline 0.5 & 0 & 1 & 0 & 1 & 7 & 1 & 14 & 0 & 217 & 0 \\
\hline 1.0 & 0 & 1 & 0 & 1 & 7 & 1 & 16 & 0 & 215 & 0 \\
\hline 1.5 & 0 & 1 & 0 & 1 & 5 & 1 & 20 & 0 & 213 & 0 \\
\hline 2.0 & 0 & 1 & 0 & 1 & 11 & 1 & 24 & 0 & 203 & 0 \\
\hline 2.5 & 0 & 1 & 0 & 1 & 11 & 1 & 26 & 0 & 201 & 0 \\
\hline 3.0 & 0 & 1 & 0 & 1 & 9 & 1 & 32 & 2 & 195 & 0 \\
\hline 3.5 & 0 & 1 & 0 & 1 & 13 & 1 & 36 & 2 & 187 & 0 \\
\hline 4.0 & 0 & 1 & 0 & 1 & 17 & 1 & 36 & 3 & 182 & 0 \\
\hline 4.5 & 2 & 1 & 0 & 1 & 19 & 1 & 39 & 3 & 175 & 0 \\
\hline 5.0 & 2 & 1 & 0 & 1 & 22 & 1 & 40 & 5 & 169 & 0 \\
\hline 5.5 & 2 & 1 & 0 & 1 & 21 & 1 & 44 & 5 & 166 & 0 \\
\hline 6.0 & 2 & 1 & 0 & 1 & 19 & 1 & 44 & 7 & 166 & 0 \\
\hline 6.5 & 2 & 1 & 0 & 1 & 18 & 1 & 44 & 10 & 164 & 0 \\
\hline 7.0 & 0 & 1 & 0 & 1 & 18 & 1 & 44 & 15 & 161 & 0 \\
\hline 7.5 & 0 & 1 & 0 & 1 & 18 & 1 & 44 & 15 & 161 & 0 \\
\hline 8.0 & 0 & 1 & 0 & 1 & 17 & 1 & 45 & 15 & 161 & 0 \\
\hline 8.5 & 0 & 1 & 0 & 1 & 17 & 1 & 43 & 17 & 161 & 0 \\
\hline 9.0 & 0 & 1 & 0 & 1 & 17 & 1 & 43 & 17 & 161 & 0 \\
\hline 9.5 & 0 & 1 & 1 & 1 & 17 & 1 & 43 & 18 & 159 & 0 \\
\hline 10.0 & 0 & 1 & 1 & 1 & 17 & 1 & 45 & 18 & 157 & 0 \\
\hline Total cases: 5061 & 10 & 21 & 2 & 20 & 305 & 21 & 728 & 152 & 3802 & 0 \\
\hline Total cases: $100 \%$ & 0.198 & 0.415 & 0.040 & 0.395 & 6.026 & 0.415 & 14.385 & 3.003 & 75.123 & 0.000 \\
\hline
\end{tabular}

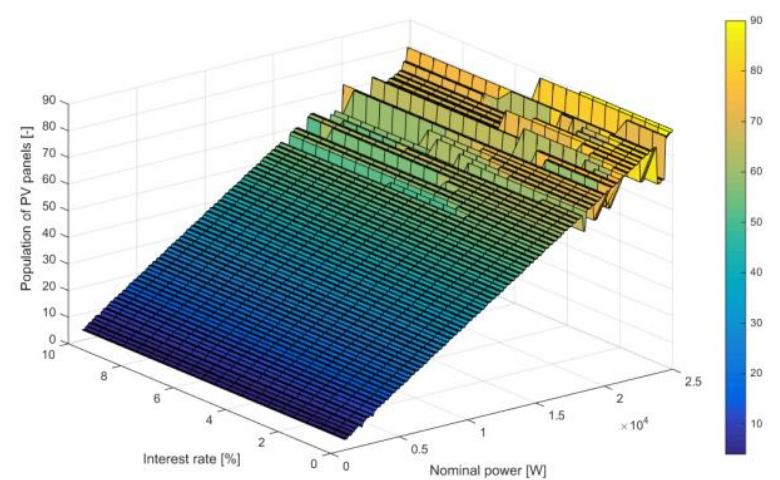

Fig. 8. Three-dimensional graph of the number of PV panels depending on the respective type in relation to the nominal power of the PV plant under configuration and the capital recovery interest rate, with increased reliability requirements for the set of $133 \mathrm{PV}$ panels.

Regarding the change of the dimensions of the roof, it is found that for powers up to $12.3 \mathrm{~kW}$ no cantilever is needed, while for higher powers the optimal expansion of the roof to minimize its construction cost leads to a non-increasing change of its respective dimensions, as shown in Fig. 9 for the $\mathrm{xOx}$ 'axis and Fig. 10 for the yOy' axis using all frame types. The same is observed for the change of the roof's extension area, as shown in Fig. 11. Usually with the increase of the roof area, the necessary number of panels are placed in order to achieve the required nominal power, unless the type of panels used changes, which can lead to a reduction of the area. Any variances in the 
dimensions of the roof and in the extension of its area for the same interest rate are due to the changes in the dimensions of the selected panels during the configuration of the PV plant of corresponding power and only.

Regarding the selection of the inverter type, the following types emerge according to the corresponding results of table 2 and of Fig. 12, which has the three-dimensional chart of the inverter type for all $205 \mathrm{PV}$ inverters in relation to the nominal power of the PV plant and the capital recovery rate:

- $\mathrm{S} / \mathrm{N}=37$, type $=$ Symo $15-3-\mathrm{M}$ of Fronius with nominal output power $15 \mathrm{~kW}$,

- $\mathrm{S} / \mathrm{N}=104$, type $=$ SG3K-S Residential singlephase inverter of the Sungrow company with nominal output power $3,5 \mathrm{~kW}$,

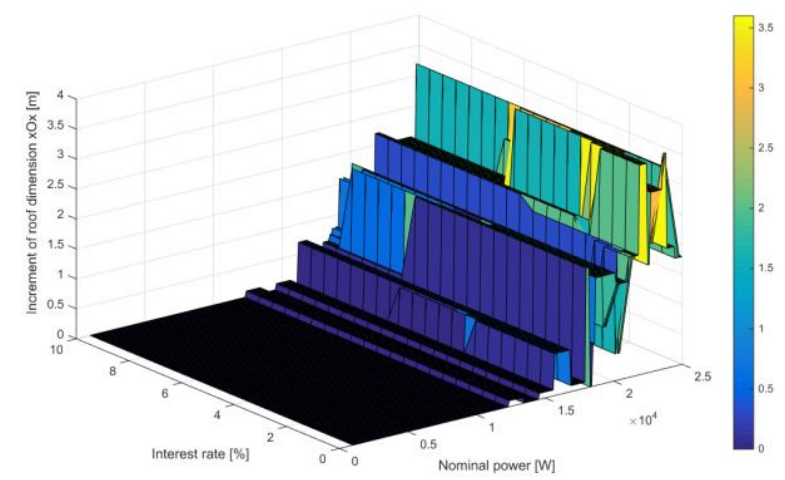

Fig. 9. Three-dimensional graph of the increase in the dimension of the roof in relation to the $\mathrm{xOx}^{\prime}$ axis as a function of the nominal power of the PV plant under configuration and the capital recovery rate, with increased reliability requirements for the set of $133 \mathrm{PV}$ panels.

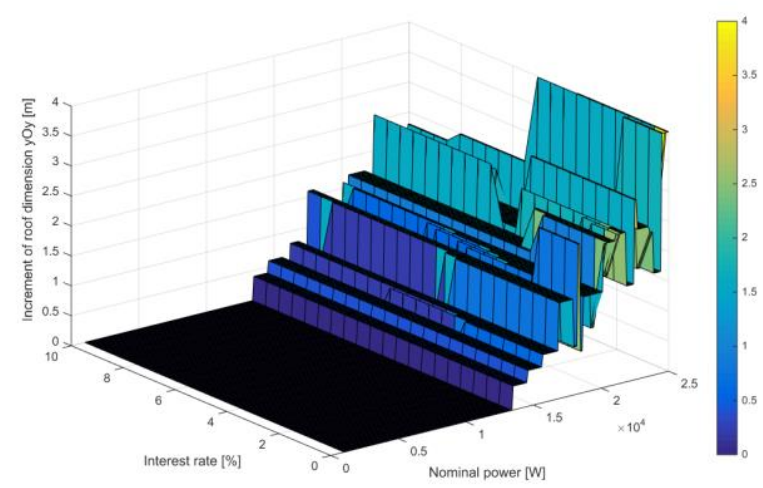

Fig. 10. Three-dimensional graph of the increase in the dimension of the roof in relation to the yOy' axis as a function of the nominal power of the PV plant under configuration and the capital recovery rate, with increased reliability requirements for the set of $133 \mathrm{PV}$ panels.

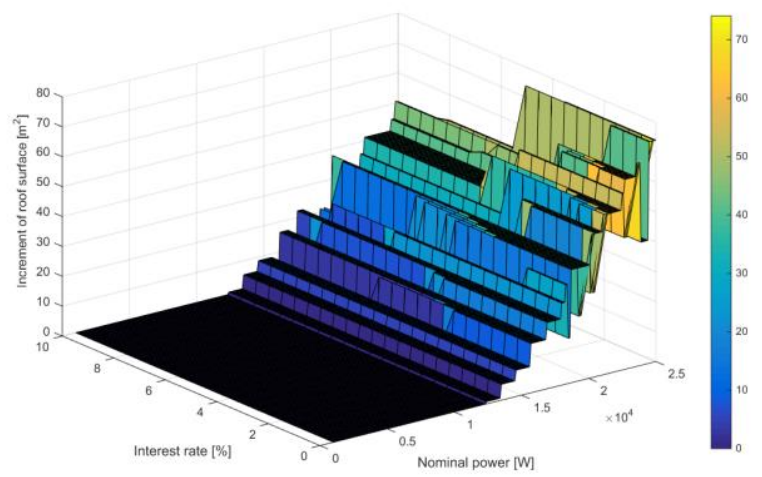

Fig. 11. Three-dimensional graph of the increase of the terrace area in relation to the nominal power of the PV plant under configuration and the capital recovery interest rate, with increased reliability requirements for the set of 133 PV panels.

- $\mathrm{S} / \mathrm{N}=108$, type $=$ SG5KTL-MT-V14 of Sungrow with nominal output power $5 \mathrm{~kW}$,

- $\mathrm{S} / \mathrm{N}=109$, type $=$ SG6KTL-MT-V13 of Sungrow with nominal output power $6 \mathrm{~kW}$,

- $\mathrm{S} / \mathrm{N}=110$, type $=$ SG8KTL-MT-V13 of Sungrow with nominal output power $8 \mathrm{~kW}$,

- $\mathrm{S} / \mathrm{N}=111$, type $=$ SG10KTL-MT-V15 of Sungrow with nominal output power $10 \mathrm{~kW}$,

- $\mathrm{S} / \mathrm{N}=183$, type= GW12KN-DT of GoodWe with nominal output power $12 \mathrm{~kW}$,

- $\mathrm{S} / \mathrm{N}=184$, type= GW15KN-DT of GoodWe with nominal output power $15 \mathrm{~kW}$,

- $\mathrm{S} / \mathrm{N}=185$, type $=$ GW17KN-DT of GoodWe with nominal output power $17 \mathrm{~kW}$.

The corresponding study shows the dominance of the inverter with S/N 108 type SG5KTL-MT-V14 of the Sungrow company with nominal output power $5 \mathrm{~kW}$ at a rate of $33.99 \%$ and then of the inverter with S/N 110 type SG8KTL-MT-V13 of Sungrow company also with nominal output power $8 \mathrm{~kW}$ in $31.59 \%$ of the cases examined, as recorded in Table 2. In fact, Sungrow covers all cases in $84.13 \%$ due to the long basic warranty period of 10 years, with the consequence that the lifespan of the respective materials is typically considered to be 15 years.

Type SG5KTL-MT-V14 with S/N 108 dominates for powers up to $6.7 \mathrm{~kW}$ when interest rates are low and up to $13.7 \mathrm{~kW}$ for high interest rates. For powers up to $16.2 \mathrm{~kW}$ the dominating type is SG8KTL-MT-V13 with S/N 110, next comes the type SG10KTL-MT-V15 with S/N 111 for powers up to $20.1 \mathrm{~kW}$, and the type GW17KN-DT with S/N 185 for powers between $23.8 \mathrm{~kW}$ and 24.4 $\mathrm{kW}$, while the other inverters are inserted in intermediate intervals. The different inverter choices for the same nominal power of the PV plant 
depending on the interest rates arise from marginal variations resulting from the participation of the ideal energy of the PV panel and the inverter's different technical specifications according to the PV panel that leads to small variations of the respective annual equivalent cost and the corresponding selection of panel and inverter types. At the same time, it is observed that inverters of relatively high nominal power are selected.

For the number of inverters required, the selection is based on both the inverter type and the rated power of the PV plant under configuration. The corresponding graph of the number of inverters in relation to the nominal power of the PV plant and the capital recovery rate is recorded in Fig. 13.

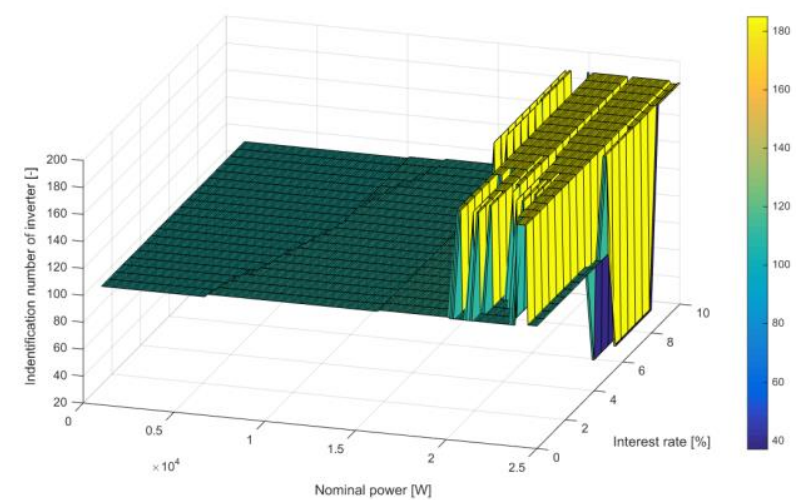

Fig. 12. Three-dimensional graph of the inverter type serial number in relation to the nominal power of the PV plant under configuration and the capital recovery interest rate, with increased reliability requirements for the sets of 133 PV panels and 205 PV inverters respectively.

Table 2: Number of occurrences and percentage optimal selection of the inverter type in terms of annual equivalent costs for various deflated interest rates for the 205 inverter types under the option of selecting from 133 types of PV panels

\begin{tabular}{|c|c|c|c|c|c|c|c|c|c|c|}
\hline \multirow{2}{*}{$\begin{array}{l}\text { Number of cases } \\
\text { Interest rate [\%] }\end{array}$} & \multicolumn{10}{|c|}{ Serial number of photovoltaic inverter type } \\
\hline & 37 & 104 & 108 & 109 & 110 & 111 & 183 & 184 & 185 & Rest cases \\
\hline 0.0 & 0 & 0 & 58 & 0 & 132 & 45 & 0 & 0 & 6 & 0 \\
\hline 0.5 & 0 & 0 & 61 & 0 & 120 & 45 & 0 & 0 & 15 & 0 \\
\hline 1.0 & 0 & 0 & 63 & 0 & 116 & 45 & 0 & 0 & 17 & 0 \\
\hline 1.5 & 0 & 0 & 66 & 0 & 109 & 45 & 0 & 0 & 21 & 0 \\
\hline 2.0 & 0 & 0 & 72 & 0 & 99 & 45 & 0 & 0 & 25 & 0 \\
\hline 2.5 & 0 & 0 & 75 & 0 & 94 & 45 & 0 & 0 & 27 & 0 \\
\hline 3.0 & 0 & 0 & 77 & 0 & 86 & 45 & 0 & 0 & 33 & 0 \\
\hline 3.5 & 0 & 0 & 80 & 0 & 79 & 45 & 0 & 0 & 37 & 0 \\
\hline 4.0 & 0 & 0 & 83 & 0 & 76 & 45 & 0 & 0 & 37 & 0 \\
\hline 4.5 & 2 & 0 & 86 & 0 & 70 & 43 & 0 & 0 & 40 & 0 \\
\hline 5.0 & 2 & 0 & 89 & 0 & 67 & 39 & 3 & 0 & 41 & 0 \\
\hline 5.5 & 4 & 0 & 91 & 0 & 64 & 37 & 2 & 0 & 43 & 0 \\
\hline 6.0 & 4 & 0 & 91 & 0 & 64 & 37 & 2 & 0 & 43 & 0 \\
\hline 6.5 & 4 & 0 & 91 & 0 & 64 & 37 & 2 & 0 & 43 & 0 \\
\hline 7.0 & 2 & 0 & 91 & 3 & 61 & 37 & 4 & 0 & 43 & 0 \\
\hline 7.5 & 2 & 0 & 91 & 6 & 58 & 37 & 4 & 0 & 43 & 0 \\
\hline 8.0 & 2 & 0 & 91 & 9 & 55 & 36 & 4 & 0 & 44 & 0 \\
\hline 8.5 & 0 & 0 & 91 & 14 & 50 & 36 & 4 & 2 & 44 & 0 \\
\hline 9.0 & 0 & 0 & 91 & 17 & 47 & 36 & 4 & 2 & 44 & 0 \\
\hline 9.5 & 0 & 1 & 91 & 20 & 44 & 35 & 4 & 2 & 44 & 0 \\
\hline 10.0 & 0 & 1 & 91 & 20 & 44 & 33 & 4 & 2 & 46 & 0 \\
\hline Total cases: 5061 & 22 & 2 & 1720 & 89 & 1599 & 848 & 37 & 8 & 736 & 0 \\
\hline Total cases: $100 \%$ & $0.435 \%$ & $0.040 \%$ & $33.985 \%$ & $1.759 \%$ & $31.595 \%$ & $16.756 \%$ & $0.731 \%$ & $0.158 \%$ & $14.543 \%$ & 0.000 \\
\hline
\end{tabular}

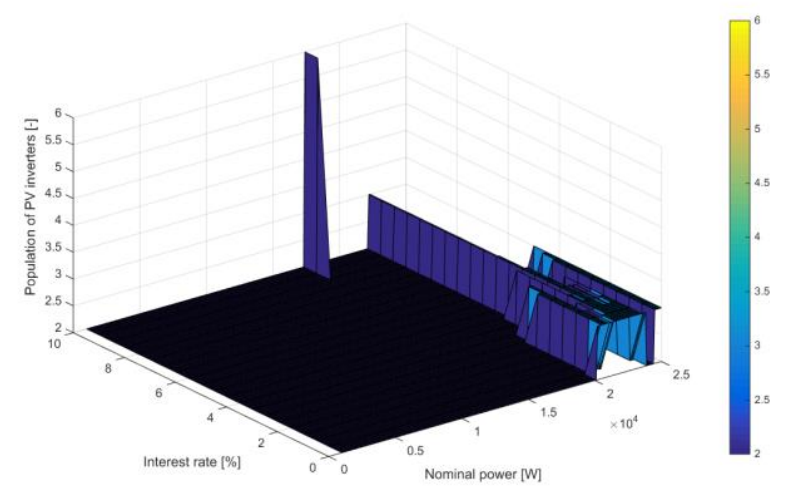

Fig. 13. Three-dimensional graph of the number of inverters depending on the nominal power of the PV plant under construction and the capital recovery rate, with increased reliability requirements for the sets of 133
PV panels and 205 PV inverters respectively.

In this case, an overwhelming predominance of the minimum inverter population equal to 2 (due to the requirement of increased reliability) is found in $94.94 \%$ of the cases considered, while the occurrence of 3 inverters is only at $5.02 \%$ (for some cases of very high power of $23 \mathrm{~kW}$ and very low interest rates) and the occurrence of 6 inverters is only $0.02 \%$ (for some cases of very high power of $25 \mathrm{~kW}$ and especially very high interest rates of $9.5 \%$ or more). The last case specifically concerns the use of the inverters with S/N 104 (SG3K5-S Residential single-phase inverter of the Sungrow company) with nominal output power of the inverter 
$3.5 \mathrm{~kW}$. Other inverter count values are not displayed in the graph.

In terms of the annual equivalent construction cost of the PV plant with increased reliability requirements depending on its rated power and the corresponding deflated capital recovery interest rate, the results are recorded in Fig. 14. If the procedure of the initial solution is repeated for the default PV panels of Solbian company [8] and the corresponding difference between the annual configuration costs of the PV plant of Fig. 15 is calculated, then it is immediately established that the use of photovoltaic panels by SOLBIAN leads to much more expensive solutions. The difference at the expense of the solution of SOLBIAN against the $\mathrm{PV}$ panels becomes greater as the power of the PV plant under construction increases and the interest rate increases. The corresponding reduction of the installation and operation costs of the PV plant achieved by the application of the proposed methodology compared to the initial solution [8] (which is also the benchmark) ranges from $61.7 \%$ to $78.2 \%$, with the higher reduction values being achieved for higher powers and lower interest rates.

The corresponding computational time for all these combinations is 50 minutes using original code in the MATLAB R2014b programming package running on an Inspiron 3593 Intel(R) Corel(TM) i7-1065G7 CPU@1.3GHz and RAM 8 GB laptop, which despite the exhaustive search and execution of all possible combinations is satisfactory and practically usable.

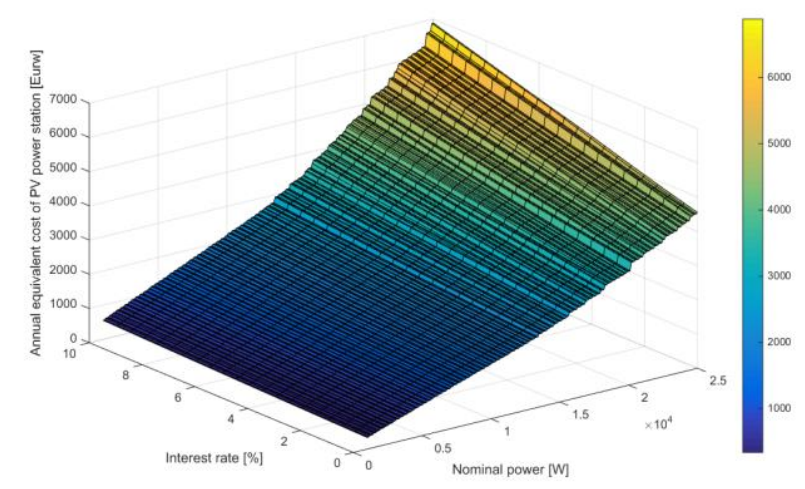

Fig. 14. Three-dimensional graph of the annual equivalent cost of construction - operation of a PV plant with increased reliability requirements for the sets of 133 PV panels and 205 PV inverters respectively depending on the nominal power of the PV plant under construction and the interest rate.

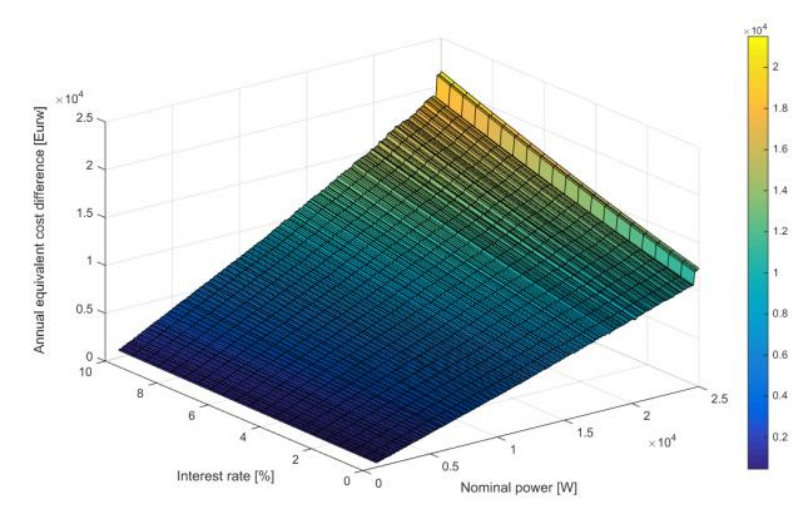

Fig. 15. Three-dimensional graph of the difference of the annual equivalent construction-operation costs of a photovoltaic plant with increased reliability requirements between the case of using PV panels of SOLBIAN company [8] and the case of selecting from the sets of $133 \mathrm{PV}$ panels and $205 \mathrm{PV}$ inverters respectively depending on the nominal power of the PV plant under construction and the capital recovery rate.

\section{Conclusion}

This paper presents a methodology for the overall evaluation of a photovoltaic plant with the aim of achieving the minimum cost for different levels of nominal power and deflated interest rate, while satisfying both the necessary technical requirements, the installation and operation costs of electromechanical components, the cost of land occupation (even if it is a roof), as well as the impact of the efficiency of individual elements of the photovoltaic plant on the generated power. The optimum system is determined from an economic point of view using the method of exhaustive search and the utilization of a large set of real commercial data of individual basic elements (PV panels and inverters) of different companies.

The methodology is applied for the real problem of a PV plant design for the power supply of the shoreline electrode substation on the isolated and uninhabited islet of Stachtoroi in the Argosaronic Gulf of Attica, Greece [8] with mean load demand up to $4.1 \mathrm{~kW}$ and peak demand load $22.3 \mathrm{~kW}$. Against the initial solution with one type of PV panel and inverter [8] all technically permissible combinations of 133 different PV panels and 205 PV inverters were examined, achieving a reduction of the total equivalent cost of installation and operation of the PV plant between $62 \%$ and $78 \%$, with a computational cost of less than an hour, despite the use of exhaustive search. The counter value is that for the same nominal power, depending on the deflated interest rate of capital recovery, there is a different optimal configuration of PV 
panels - inverters - roof extension. Of course, this problem is limited, as shown in Fig. 7 to 13.

\section{References:}

[1] M. Das, M. A. Kumar Singh, A. Biswas, Techno-economic optimization of an off-grid hybrid renewable energy system using metaheuristic optimization approaches - Case of a radio transmitter station in India, Energy Conversion and Management, Vol. 185, 2019, pp. 339-352.

[2] B. Loganathan, H. Chowdhury, I. Mustary, S. M. Sony, M. M. Rana, F. Alam, Design of a hybrid household power generation system for a rural area: A case study for Oodnadatta, Australia, Energy Procedia, Vol. 160, 2019, pp. 827-833.

[3] T.A. Boghdady, A.J. Alamer, M.M. Yousef, A.M.Elshafee, M.A. Mostafa Hassan, A. Monem Seif, Technical and economic study of powering poultry farm in Egypt using PVbiomass on-grid energy generation system: Case study, WSEAS Transactions on Power Systems, Vol.16, 2021, pp.67-77.

[4] M.M. El-Yamany, S.O. Abdullatif, H.A. Ghali, Investigating the techno-economic utility of integrating an optimized $\mathrm{PV} /$ diesel hybrid system in an entire oil field in the westerndessert in Egypt, WSEAS Transactions on Power Systems, Vol.16, 2021, pp.104-120.

[5] G. J. Tsekouras, F. D. Kanellos, Optimal operation of ship electrical power system with energy storage system and photovoltaics: Analysis and application, WSEAS Transactions on Power Systems, Vol. 8, No. 4, 2013, pp. 145-155.

[6] A. Giallanza, M. Poretto, G. L. Puma, G. Marannano, A sizing approach for stand-alone hybrid photovoltaic-wind-battery systems: A Sicilian study case, Journal of Cleaner Production, Vol. 199, 2018, pp. 817-830.

[7] T. Mao, M.S. Javed, Intergrated sizing of hybrid PV-wind-battery system for remote island considering the saturation of each renewable energy resource, Energy conversion and management, Vol. 182, 2019, pp. 178-190.

[8] P.M. Deligianni, G.J. Tsekouras, C.D. Tsirekis, V.T. Kontargyri, F. D. Kanellos, P.A. Kontaxis, Techno-economic optimization analysis of an autonomous photovoltaic power system for a shoreline - electrode -station of HVDC link: Case study of electrode station on the small island of Stachtoroi for Attica-Crete interconnection, Energies, 2020, paper no. 1305550, pp.1-49.
[9] A. Yahiaoui, F. Fodhil, K. Benmansour, M. Tadjine, N. Cheggaga, Grey wolf optimizer for optimal design of hybrid renewable energy system PV-diesel generator-battery: Application to the case of Djanet city of Algeria, Solar Energy, Vol. 158, 2017, pp. 941951.

[10] A. Kaabeche, Y. Bakelli, Renewable hybrid system size optimization considering various electrochemical energy storage technologies, Energy conversion and management, Vol. 193, 2019, pp. 162-175.

[11] A.C. Duman, O. Guler, Techno-economic analysis of off-grid $\mathrm{PV} /$ wind/fuel cell hybrid system combinations with a comparison of regularly and seasonally occupied households, Sustainable cities and society, Vol. 42, 2018, pp.107-126.

[12] S. V. Papaefthymiou, E. G. Karamanou, S. A. Papathanassiou, M. P. Papadopoulos, A windhydro-pumped - storage station leading to high RES penetration in the autonomous island system of Ikaria, IEEE Transactions on Sustainable Energy, Vol. 1, no.3, 2010, pp. 163-172.

[13] G.S.Chaurasia, A.K.Singh, S.Agrawal, N.K. Sharma, A meta-heuristic firefly algorithm based smart control strategy and analysis of a grid connected hybrid photovoltaic/wind distributed generation system, Solar Energy, Vol. 150, 2017, pp. 265-274.

[14] CIGRE Working Group B4.61. General Guidelines for HVDC Electrode Design, 1st ed.; CIGRE: Paris, France, 2017; Volume 675, pp. $1-150$.

[15] http://www.dieselserviceandsupply.com/Diesel Fuel Consumption.aspx

[16] https://solbian.gr/index.php?route=product/pro duct\&path $=20 \quad 62$ \&product $\mathrm{id}=74$

[17] https://www.europe-solarstore.com/solarpanels/manufacturer.html

[18] https://www.europe-solarstore.com/solarinverters.html 
Contribution of Individual Authors to the Creation of a Scientific Article (Ghostwriting Policy)

George J. Tsekouras carried out the conceptualization, the references investigation, the methodology, the programming, the simulation, the visualization and the writing.

Panagiota M. Deligianni carried out the data investigation, the methodology, the programming, the simulation, the visualization and the writing.

George A. Vokas carried out the conceptualization and the visualization.

Antonios X. Moronis carried out the methodology and the visualization.

Constantinos D. Tsirekis carried out the programming and the simulation.

Anastasios D. Salis carried out the data investigation for PV inverters and the simulation.

Christos N. Bolakis carried out the data investigation for PV panels and the simulation.

Sources of Funding for Research Presented in a Scientific Article or Scientific Article Itself

No funding was received for conducting this study.

\section{Conflict of Interest}

The authors have no conflicts of interest to declare that are relevant to the content of this article.

Creative Commons Attribution License 4.0 (Attribution 4.0 International, CC BY 4.0)

This article is published under the terms of the Creative Commons Attribution License 4.0

https://creativecommons.org/licenses/by/4.0/deed.en 